Article

\title{
Capsaicin Synthesis Requires in Situ Phenylalanine and Valine Formation in in Vitro Maintained Placentas from Capsicum chinense
}

\author{
Fray M. Baas-Espinola, Lizbeth A. Castro-Concha, Felipe A. Vázquez-Flota and \\ María L. Miranda-Ham * \\ Unidad de Bioquímica y Biología Molecular de Plantas, Centro de Investigación Científica de Yucatán, A.C., \\ Calle 43 \# 130, Chuburná de Hidalgo, Mérida, Yucatán 97200, Mexico; segarfield_88@hotmail.com (F.M.B.-E.); \\ liarcaco@cicy.mx (L.A.C.-C.); felipe@cicy.mx (F.A.V.-F.) \\ * Correspondence: mirham@cicy.mx; Tel.: +52-999-942-8330 (ext. 228); Fax: +52-999-981-3000 \\ Academic Editor: Pin Ju Chueh \\ Received: 26 April 2016; Accepted: 15 June 2016; Published: 21 June 2016
}

\begin{abstract}
Capsaicinoids (CAP) are nitrogenous metabolites formed from valine (Val) and phenylalanine (Phe) in the placentas of hot Capsicum genotypes. Placentas of Habanero peppers can incorporate inorganic nitrogen into amino acids and have the ability to secure the availability of the required amino acids for CAP biosynthesis. In order to determine the participation of the placental tissue as a supplier of these amino acids, the effects of blocking the synthesis of Val and Phe by using specific enzyme inhibitors were analyzed. Isolated placentas maintained in vitro were used to rule out external sources' participation. Blocking Phe synthesis, through the inhibition of arogenate dehydratase, significantly decreased CAP accumulation suggesting that at least part of Phe required in this process has to be produced in situ. Chlorsulfuron inhibition of acetolactate synthase, involved in Val synthesis, decreased not only Val accumulation but also that of CAP, pointing out that the requirement for this amino acid can also be fulfilled by this tissue. The presented data demonstrates that CAP accumulation in in vitro maintained placentas can be accomplished through the in situ availability of Val and Phe and suggests that the synthesis of the fatty acid chain moiety may be a limiting factor in the biosynthesis of these alkaloids.
\end{abstract}

Keywords: Solanaceae; Habanero pepper; inhibitors; chlorsulfuron; p-fluorophenylalanine

\section{Introduction}

Chili plants (Capsicum spp.) have long been valued worldwide as an important source of bioactive compounds that are beneficial to human health. Their fruits are known not only as an important source of vitamins, carotenoids and phenolic compounds, all of which possess important antioxidant properties, but also for their pungency [1,2].

Capsaicinoids (CAP), the pungent principle of peppers, are exclusively produced and accumulated in placentas of the hot genotypes of peppers (Capsicum). The ability to synthesize CAP is related to the presence of at least one functional acyltransferase allele (AT3) at the Pun1 locus [3]. Recently, capsaicinoid synthase (CS) activity has been ascribed to AT3 [4]. Non-pungent peppers carry a non-functional allele, which lacks a $2.5 \mathrm{~Kb}$ region at the $5^{\prime}$ end, bearing part of the promotor and the first $735 \mathrm{bp}$ of the open reading frame [5]. Although the qualitative component of pungency is controlled by Pun1 (formerly known as locus C; $[3,5]$ ), the basis for the quantitative component of this trait is less known. Wide variations in the amounts of CAP produced by the different hot pepper genotypes occur [6], and even in highly isogenic lines, important variations might arise, depending on environmental conditions and pod position in the stem [7]. This suggests that the expression of CAP biosynthetic machinery can be modulated by external factors. CAP synthesis initiates from 
the amino acids phenylalanine and valine, from which the phenolic and acyl moieties are formed, respectively (Figure 1). Being a nitrogenous metabolite, nitrogen availability affects CAP accumulation in pepper pods [8]. Moreover, these effects are related to nitrogen availability in the placenta, the tissue responsible of CAP biosynthesis. An increase in the availability of nitrate in this tissue promoted their accumulation $[9,10]$. Interestingly, salicylic acid (SA) and methyl jasmonate (MeJa) induction of $\mathrm{CAP}$ accumulation in in vitro cultured pepper placentas required the activation of primary nitrogen assimilation, through the glutamine synthetase/glutamate synthase (GS/GOGAT) cycle [11]. In this way, it is clear that besides its biosynthetic capacity for CAP, pepper placentas also display the ability to secure to some extent the availability of the amino acids required in such a process. In order to determine the participation of the placental tissue as a supplier of these amino acids, herein we have analyzed the effects of blocking the synthesis of Val and Phe by using specific enzyme inhibitors. Hence, to rule out the possible participation of external sources, isolated placental tissues were maintained in vitro.

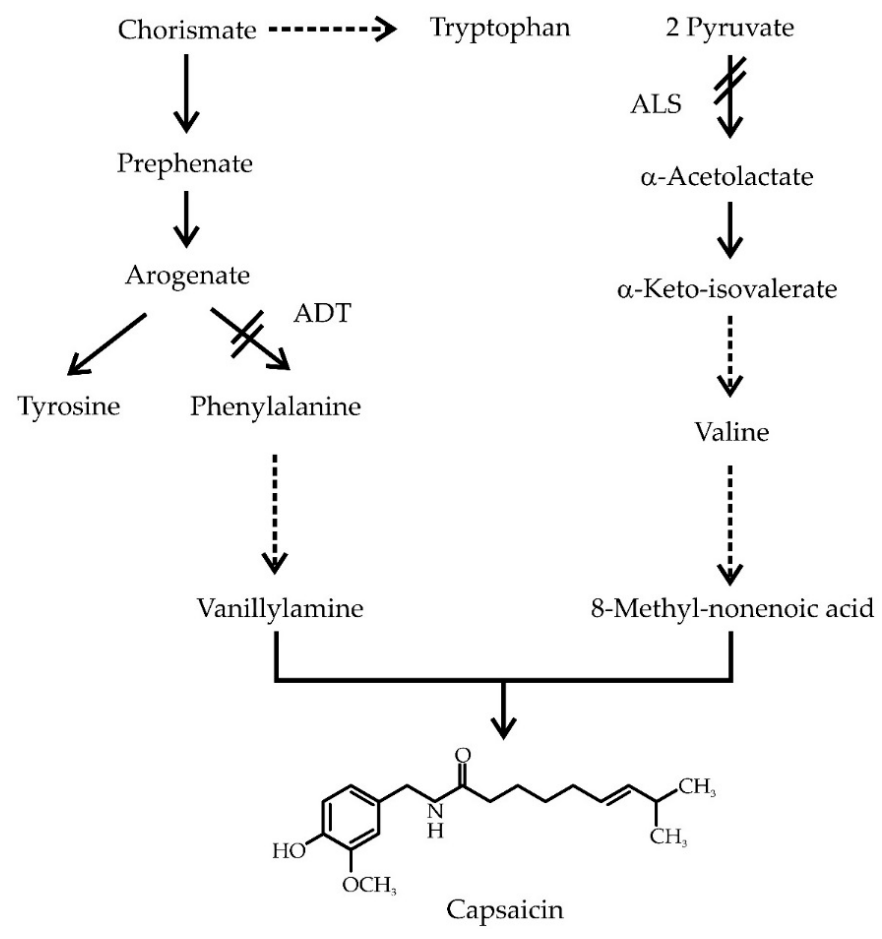

Figure 1. Schematic representation of phenylalanine (Phe) and valine (Val) biosynthetic pathways and their relation to capsaicinoids (CAP) synthesis.

It has been demonstrated that both amino acids have been shown to be required to increase CAP synthesis in non-differentiated cell cultures $[12,13]$. However, under normal conditions, both Phe (2-22 nmol.g $\mathrm{g}^{-1} \mathrm{FW}$; [14]) and Val (2-9 nmol.g ${ }^{-1} \mathrm{FW}$; [14]) cell pools in C. chinense placentas are very low, suggesting that their synthesis must be triggered only when it is required to satisfy specific demands [14].

\section{Results}

\subsection{Pepper Placentas Are Able to Synthesize both Phe and Val in Situ}

Acetolactate synthase (ALS) represents the first committed step in the synthesis of Val, whereas arogenate dehydratase (ADT), directly channels arogenate towards Phe formation (Figure 1). Both enzymes have been shown to play critical roles in controlling the synthesis of each amino acid and were chosen as markers for the functionality of the corresponding pathways. Three different 
pepper tissues (leaves, pericarp and placentas) were analyzed for both ALS and ADT enzyme activities. ADT showed values between 4.0 and $6.2 \mathrm{nmol}$ phenylalanine $\mathrm{min}^{-1} \cdot \mathrm{mg}^{-1}$ protein, with pericarps displaying the highest activities, about 2-fold higher than that found in placentas (Figure 2A). ALS activity levels were in a similar range (i.e., between 1.6 and $6.4 \mathrm{nmol}$ acetoin produced $\mathrm{min}^{-1} \cdot \mathrm{mg}^{-1}$ protein), with pericarps and placentas presenting much higher activities over leaves (Figure 2B). In both cases, enzyme activity values were similar to previous reports from different plant species, such as tomato, petunia and pea [15-19]. This is the first report of these enzymes being detected in Habanero pepper tissues, and thus, confirming Mazourek's metabolic model for capsaicinoids synthesis, based on bioinformatic data [20].

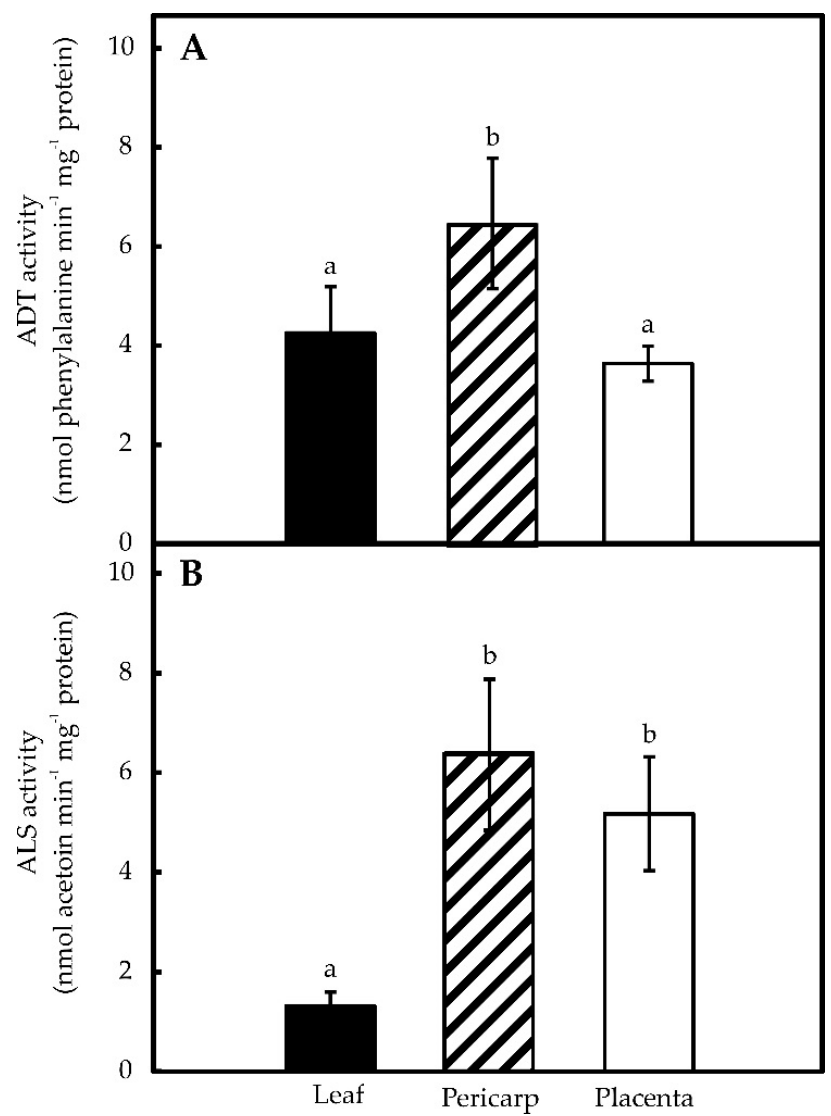

Figure 2. Arogenate dehydratase (ADT) (A) and acetolactate synthase (ALS) (B) specific activities in leaves, pericarps and placentas from C. chinense. Data represent mean \pm standard deviation (S.D.) of three independent experiments with three replicates. Bars labeled with different letters are significantly different (Tukey's test, $\alpha=0.05$ ).

\subsection{Phe and Val Accumulation in Pepper Placentas Are Sensitive to $p$-Fluorophenylalanine ( $p-F P$ ) and Chlorsulfuron $(\mathrm{Cln})$}

Once the ability of placentas to synthesize Phe and Val was established, their requirement for CAP synthesis was analyzed by blocking their formation through the use of p-FP and Cln, for the inhibition of ADT (Phe) and ALS (Val), respectively. Maximal ADT inhibition (86\%) was attained using $500 \mu \mathrm{M}$ of p-FP for $72 \mathrm{~h}$ on placentas cultured in vitro (Figure 3A). Maximal ALS inhibition in placentas $(84 \%)$ was obtained with $90 \mathrm{nM}$ Cln after $12 \mathrm{~h}$ of exposure (Figure 3B). Higher doses (120 nM) and longer exposures $(18 \mathrm{~h})$ did not result in any further inhibition (data not shown). In this way, pepper ALS showed sensitivity to Cln similar to that from pea [15]. It should be mentioned that neither Cln, nor p-FP displayed reciprocal inhibition on each other targets (Figure S1). Furthermore, viability of the placentas, estimated as the exclusion of a vital dye (Evans' blue), was not affected by the inhibitors' treatments (Figure S2). 

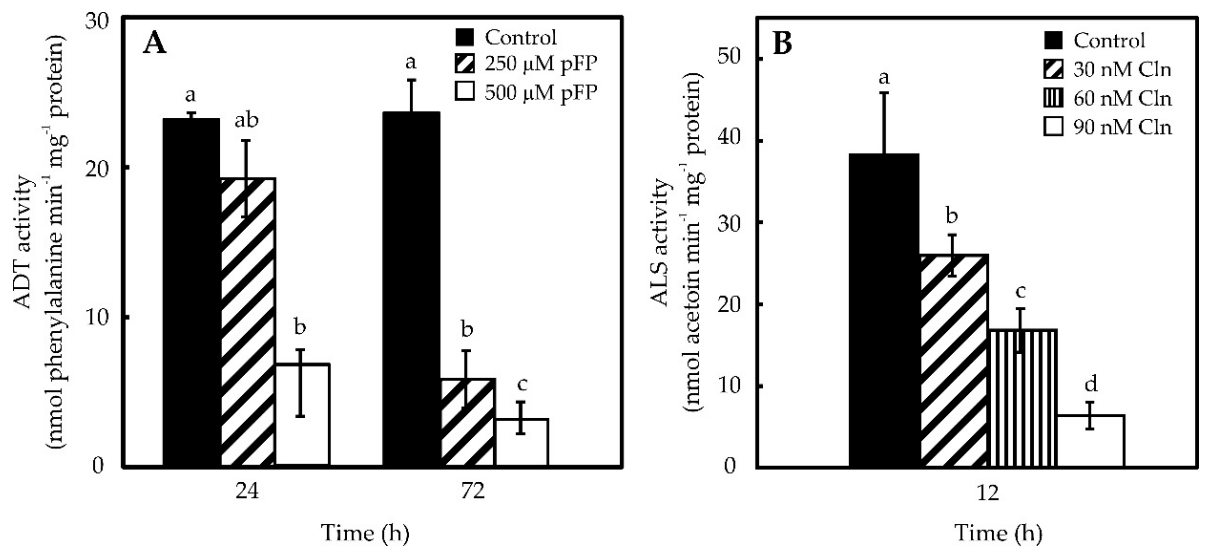

Figure 3. Inhibition of ADT (A) and ALS (B) specific activities in in vitro maintained placentas. Data represent mean \pm standard deviation (S.D.) of three independent experiments with three replicates. Bars labeled with different letters are significantly different (Tukey's test, $\alpha=0.05$ ).

\subsection{Blocking Phe and Val Synthesis Reduces CAP Accumulation in Pepper Placentas}

ADT inhibition (Figure 4A) practically annulled Phe pool, presenting no effect over Val accumulation (Figure 4C). On the other hand, the inhibition of ADT provoked an $80 \%$ decrease in Val content (Figure 4D), but also a ca. 50\% decrease in Phe contents (Figure 4B). In this way, the blockage of the selected enzymes effectively reduced the accumulation of both amino acids. Correspondently, CAP contents were also reduced by the inhibitors' treatments, although differential effects could be observed (Figure 5), since inhibition of Phe synthesis (500 mM p-FP for $72 \mathrm{~h}$ ) only lowered CAP levels by 37\% (Figure 5A), whereas Val inhibition (Cln $90 \mathrm{nM}$ for $12 \mathrm{~h}$ ) decreased CAP content up to $50 \%$ (Figure $5 \mathrm{~B}$ ). No further effects were noted by increasing neither the inhibitor doses, nor the exposure times (data not shown). In this way, locking up Phe and Val availability resulted in reduced CAP formation.
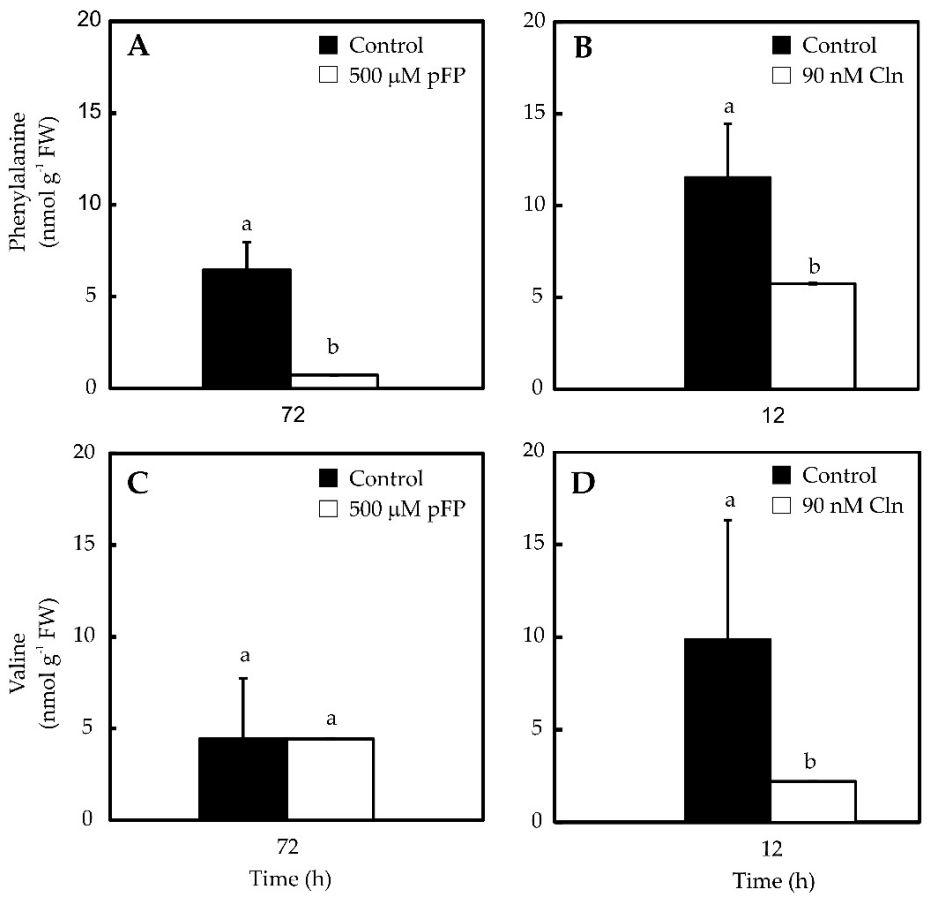

Figure 4. Phe (A and B) and Val (C and D) contents in placentas exposed to p-FP (A and C) and Cln (B and D). Data represent mean \pm standard deviation (S.D.) of three independent experiments with three replicates. Bars labeled with different letters are significantly different (Tukey's test, $\alpha=0.05$ ). 


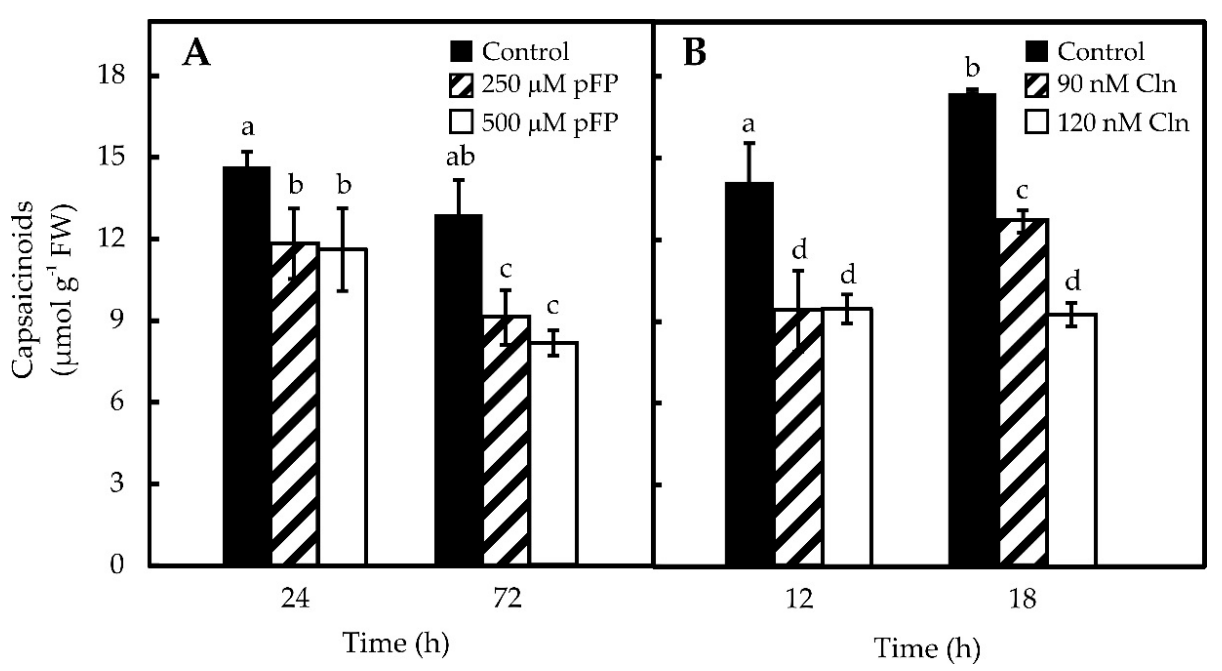

Figure 5. Effect of inhibition of Phe (A) and Val (B) synthesis on CAP contents in pepper placentas maintained in vitro. Data represent mean \pm standard deviation (S.D.) of three independent experiments with three replicates. Bars labeled with different letters are significantly different (Tukey's test, $\alpha=0.05$ ).

The relative abundance of the transcripts corresponding to the enzymes under study was also analyzed in the placentas treated with the inhibitors. Interestingly, hampering the synthesis of both amino acids led to an increase in the corresponding transcript levels (Figure 6). However, differences in the extent of these effects were noticed, i.e., inhibition of Val synthesis increased transcript accumulation for both $A D T$ and $A L S$, although in a more pronounced fashion for ADT (Figure 6A); in contrast, the use of either inhibitor augmented ALS mRNAs in a similar fashion (Figure 6B).
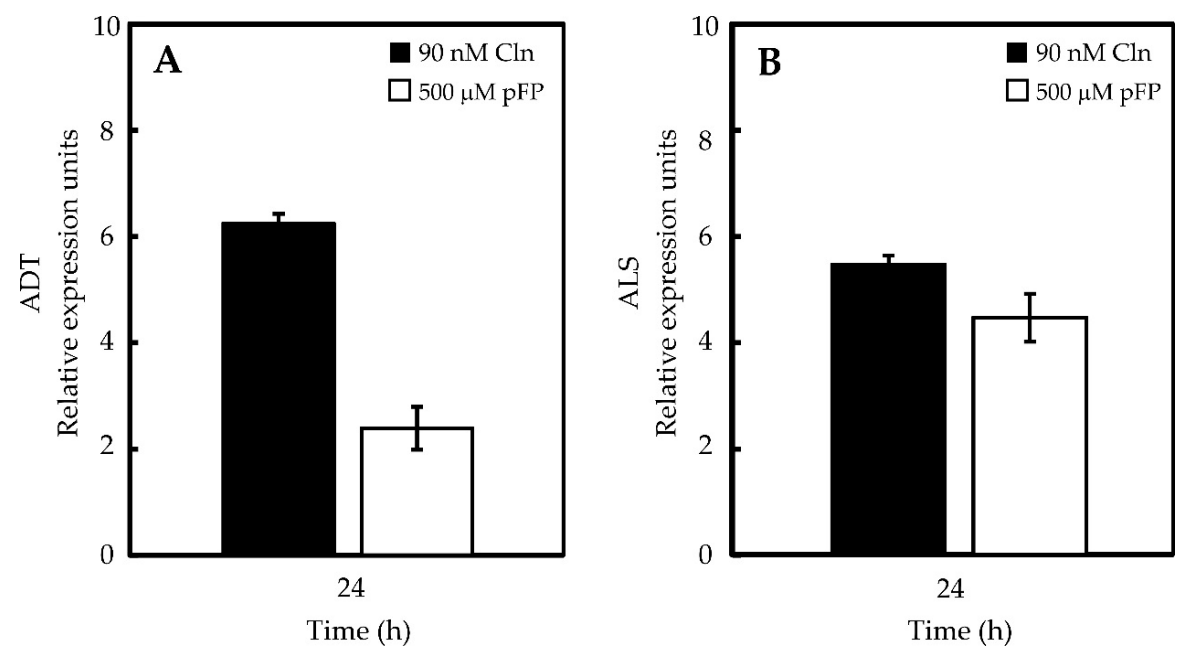

Figure 6. mRNA relative abundance of $A D T(\mathbf{A})$ and $A L S(\mathbf{B})$ in placentas maintained in vitro. Gene transcripts were quantified using the cycle threshold value $(\mathrm{Ct})$, using actin as a reference.

All together, these data suggest that CAP accumulation in isolated placentas responded to decreases in the internal availability of the required amino acids, suggesting that a coordinate mechanism channeling them towards CAP synthesis is operating.

\section{Discussion}

The committed reactions for the synthesis of Phe, tyrosine and tryptophan initiate with the central intermediary chorismate and a strict regulatory mechanism controls the balance among them (Figure 1). Arogenate dehydratase (ADT; EC 4.2.1.91), which catalyzes the last step in Phe synthesis, plays a major 
role in this mechanism [19] (Figure 1). On the other hand, the synthesis of the branched amino acids, Val included, requires a block of four common enzymes, with acetolactate synthase (ALS; EC 2.2.1.6), having a critical participation in the regulation of the process (Figure 1).

The capacity of hot pepper genotypes to synthesize CAP is genetically controlled at the Pun1 locus, which behaves as a single dominant and epistatic trait [3]. Nevertheless, CAP accumulation is affected by environmental and developmental factors [21,22]. In this way, variations in CAP contents can be ascribed to both genetic factors and plants' interactions with their environment. Moreover, CAP levels may also diminish, due to chemical hydrolysis, photo-oxidation [23], enzymatic oxidation [24] or conjugation mediated by glycosyltransferases [25]. Placenta is the only tissue expressing the genes for CAP synthesis and it can convert exogenously supplied Phe and Val in CAP [26]. However, the actual origin of these amino acids, either internal or external to this tissue, has not been determined. Phe synthesis takes place in the chloroplasts of photosynthetic tissues and the possible participation of cytosol has been proposed for other tissues [19]. In fact, transcripts putatively involved in Phe metabolism have been detected in massive sequencing projects of pepper fruits [27,28]. We have shown that protein extracts from isolated placentas display ADT enzyme activity (Figure 2), which in addition was shown to be sensitive to p-FP, a specific inhibitor (Figure 3). Moreover, blocking Phe synthesis, through the inhibition of ADT, also significantly decreased CAP accumulation suggesting that at least part of Phe required in this process might have been produced internally in the placenta. Besides the phenolic moiety, derived from Phe, CAP formation requires an acyl lateral chain derived from Val. Chlorsulfuron inhibition of ALS, which initiates Val formation from pyruvate (Figure 3), also decreased Val and CAP accumulation (Figures 4 and 5), thus suggesting that the requirement for this amino acid can also be fulfilled by the same tissue.

Variations in soil nitrate availability affected its own contents in placentas and directly impacted CAP contents [9]. This suggests that this tissue possess the biosynthetic potential to assimilate nitrate and then to transform it to the required amino acids: Val and Phe. This is further demonstrated by the fact that isolated placentas maintain their ability to synthesize these secondary metabolites, when cultured in vitro with ammonia and nitrate as sole nitrogen sources [29]. Moreover, the induction of CAP accumulation in placentas cultured in vitro by adding SA and MeJa required primary ammonia assimilation, through the activation of the GS/GOGAT cycle [11]. Our results show that affecting the accumulation of Val and/or that of Phe in placentas also reduces CAP accumulation. In cell suspensions, both Val [13] and Phe [30] availability have been shown to be limiting factors for CAP accumulation. However, CAP amounts in non-differentiated cultures are frequently low, perhaps due the lack of the specialized structures required for its accumulation [31]. The use of entire tissues, which preserve such structures, may represent a better model. Interestingly, when Val synthesis was inhibited, CAP content was diminished in a more pronounced fashion than by inhibiting Phe synthesis ( $50 \%$ vs. $37 \%$ ), which suggests that Val synthesis could be a limiting factor in this process. The fact that by inhibiting Val synthesis, Phe content diminishes concomitantly, but that the inhibition of Phe does not affect Val content, suggests that Phe synthesis might be subordinated to the synthesis or availability of Val in placentas. Free amino acid pools are strictly controlled in plant cells and the content of one amino acid is kept in a precise balance with the others. Frequently, the internal concentration of one amino acid might control to some extent the synthesis of others, including those not biosynthetically related [32].

It has been proposed that in order to increase the production of secondary metabolites, the interface between primary and secondary metabolism could be genetically manipulated [33], so this study establishes the basis for the fundamental role of primary nitrogen metabolism in placental tissues for CAP synthesis. In this way, the use of an in vitro system to maintain isolated placentas has resulted in a valuable asset, since environmental conditions can be strictly monitored, so the effects due to one sole factor can be observed [34] and the use of a differentiated tissue allows obtaining data on the regulatory mechanisms closer to those that function in the whole plant, where several cell types are usually involved [31,35]. 
Summarizing, our data demonstrates that CAP accumulation in in vitro maintained placentas can be accomplished through in situ availability of Val and Phe and suggests that the synthesis of the fatty acid chain from Val may be a limiting factor in these alkaloids' biosynthesis.

\section{Materials and Methods}

\subsection{Plant Material}

Habanero pepper plants (C. chinense Jacq.) var. Chak k'an-iik were cultivated in a greenhouse at the Centro de Investigación Científica de Yucatán (Mérida, Yucatán, México, N 21 $02^{\prime} 38^{\prime \prime}$, W 89 $38^{\prime} 22^{\prime \prime}$, $8 \mathrm{~m}$ above sea level). Plants were grown over a mixture of soil, perlite, vermiculite, peat moss and coconut fiber, and watered to full field capacity every other day. They were fertilized once a week with MaxiGro ${ }^{\circledR}$ y MaxiBloon ${ }^{\circledR}$ (General Hydroponics). Unripened fruits were collected from the same plant stratum (60-80 cm from soil level, plants' average height $1.2 \mathrm{~m}$ ), washed with commercial soap and thoroughly rinsed in running tap water. Green pods $(45 \times 25 \mathrm{~mm}$; length $\times$ width) were collected approximately 25 days post anthesis (DPA). Placental in vitro system was established using five whole, isolated placentas (approx. $3 \mathrm{~g}^{-1} \mathrm{FW}$ ) maintained for the duration of the experiments in Erlenmeyer flasks containing $40 \mathrm{~mL}$ of MS medium [36] supplemented with $30 \mathrm{~g} \cdot \mathrm{L}^{-1}$ sucrose without growth regulators. Flasks were maintained at $25^{\circ} \mathrm{C}$, with continuous light and gentle shaking $(80 \mathrm{rpm})$ for the duration of the inhibition experiments.

\subsection{Inhibition of Phe and Val Synthesis}

Phenylalanine and valine synthesis were blocked using p-FP and Cln, respectively. Inhibitor treatments (time and dose) were experimentally determined, applying up to $500 \mu \mathrm{M}$ during 24 and $48 \mathrm{~h}$ for p-FP [30] and up to $90 \mathrm{nM}$ for 12 and $18 \mathrm{~h}$ for Cln [37] to the placentas in the in vitro system described above. Cln was dissolved in tetrahydrofuran (THF) to a concentration of $12 \mu \mathrm{M}$ and diluted in $5 \mathrm{mM} \mathrm{K}_{2} \mathrm{HPO}_{4}$ (pH 7.5), whereas p-FP was dissolved in water. Both were filter-sterilized prior to application. Samples were collected, as indicated in figures, frozen with liquid nitrogen and stored at $-80^{\circ} \mathrm{C}$ until analysis. Control flasks were subjected to the same manipulations, except that THF, phosphate buffer or water were added instead of the inhibitors. Samples were used to determine ADT and ALS specific activities and mRNA's levels, as well as Phe, Val and CAP contents.

\subsection{Determination of ADT and ALS Specific Activities}

Enzyme activities were assayed in protein extracts obtained from pulverized frozen placentas. Powder was mixed with the extraction buffer $(50 \mathrm{mM}$ Tris-HCl, $\mathrm{pH} 8.5,5 \mathrm{mM}$ 2-mercaptoethanol and $5 \%(p / v)$ polyvinylpolypyrrolidone) in a 1:2 ( $p / v)$ ratio. The slurry was homogenized with a Polytron for $2 \mathrm{~min}$ and then, centrifuged at 20,400 $\mathrm{g}$ for $30 \mathrm{~min}$. All manipulations were performed at $4{ }^{\circ} \mathrm{C}$. Total protein extracts were used in the enzymatic assays. ALS activity was measured in a reaction mixture containing $20 \mathrm{mM}$ phosphate buffer $\mathrm{pH} 7.0,20 \mathrm{mM}$ pyruvate, $0.5 \mathrm{mM}$ thiamine, $0.5 \mathrm{mM}$ $\mathrm{MgCl}_{2}, 10 \mu \mathrm{M} \mathrm{FAD}^{+}$and 1-5 $\mu \mathrm{g}$ total protein [15]. Resulting acetolactate was converted to acetoin by adding $50 \mu \mathrm{L} 6 \mathrm{~N} \mathrm{H}_{2} \mathrm{SO}_{4}$ and then quantified at $525 \mathrm{~nm}$, in the presence of $500 \mu \mathrm{L} 0.5 \%$ creatine and $500 \mu \mathrm{L} \mathrm{5 \%} \alpha$-naphtol, prepared in $2.5 \mathrm{~N} \mathrm{NaOH}$. In order to estimate ADT activity, arogenate had to be enzymatically prepared from prephenate [38], using a partially purified prephenate aminotransferase (PAT; EC 2.6.1.78) [39] from C. chinense leaves. ADT activity was measured in a reaction mixture containing $50 \mathrm{mM}$ Tris- $\mathrm{HCl}(\mathrm{pH} 7.5), 2.5 \mathrm{mM}$ arogenate, $0.25 \mathrm{mM}$ Tyr, $1 \mu \mathrm{M}$ leupeptin, $1 \mu \mathrm{M}$ pepstatin, and $0.25-1 \mu \mathrm{g}$ total protein in a final volume of $200 \mu \mathrm{L}$ [40]. The mixture was incubated for one minute at $32{ }^{\circ} \mathrm{C}$ and then added an internal standard (0.833 mM glycine) and $100 \mu \mathrm{L}$ OPA (54 mg OPA dissolved in $1 \mathrm{~mL}$ ethanol, $9 \mathrm{~mL} 0.4 \mathrm{M}$ sodium borate $\mathrm{pH} 9.4$ and $200 \mu \mathrm{L}$ 2-mercaptoethanol). The reaction product (Phe) was derivatized for $90 \mathrm{~s}$ at room temperature, and then injected to an HPLC coupled with a fluorescence detector. Mobile phase was water-methanol $(2: 3 ; v / v)$, flux: $1 \mathrm{~mL} / \mathrm{min}$ and running time: $6 \mathrm{~min}$. Derivative reaction products were detected at $360 \mathrm{~nm}$ (excitation) and $455 \mathrm{~nm}$ (emission). The range for the Phe standard curve was 0-100 nmol. ALS activity was defined as nmol 
acetoin $\mathrm{min}^{-1} \cdot \mathrm{mg}^{-1}$ protein, whereas ADT activity was expressed as nmol Phe $\mathrm{min}^{-1} \cdot \mathrm{mg}^{-1} \mathrm{protein}$ Protein content was determined according to Peterson [41].

\subsection{Determination of Metabolites in Placental Tissues}

Phe and Val were separated and quantified by HPLC, as OPA-derivatives. CAP were quantified in placentas, as well as in the culture media, according to Collins et al. [42].

\subsection{ADT and ALS mRNAs' Relative Abundance}

Total RNA was extracted using the method described by Rubio-Piña and Vázquez-Flota [43]. Primers' sequences were designed according to ADT (EU616545) and ALS (EU616547) reported NCBI sequences from Capsicum annuum [20]. For ADT primer sequences were: forward 5'-AACCAATAATTCCACGAACCG-3' , reverse 5'-CATTTGCATCGTCCACTAGCC-3' and for ALS, forward 5'-TGCCATCCCTCCACAATATGCT-3', reverse 5'-ATTCTTCTGCCACCTTAGCCTC-3'. Samples were treated with DNAse I (Ambion) and cDNA was synthetized with AMV reverse transcriptase (Applied Biosystems). RT-PCR was performed using SuperScript ${ }^{\circledR}$ III One-Step RT-PCR with Platinum ${ }^{\circledR}$ Taq. The reaction mixture included in final volume of $20 \mu \mathrm{L}: 10 \mu \mathrm{L} 2 \times$ SYBR Green PCR Master Mix $(1 \times), 600 \mathrm{nM}$ forward primer $(0.6 \mu \mathrm{L}), 600 \mathrm{nM}$ reverse primer $(0.6 \mu \mathrm{L}), 75 \mathrm{ng}$ RNA $(\sim 2 \mu \mathrm{L})$ and $6.8 \mu \mathrm{L}$ RNAse-free water. RT-PCR conditions were $10 \mathrm{~min}, 95^{\circ} \mathrm{C}, 40$ cycles: (a) denaturation: $15 \mathrm{seg}, 95^{\circ} \mathrm{C}$; (b) aligment/extension: $1 \mathrm{~min}, 60^{\circ} \mathrm{C}$ (for ADT and ALS; $55^{\circ} \mathrm{C}$ for actin) and (c) extension: $72{ }^{\circ} \mathrm{C}, 30 \mathrm{seg}$. Control samples were used to estimate differences in gene expression levels, according to the equation $2^{-\Delta \Delta C_{\mathrm{T}}}[44]$.

\subsection{Data Analysis}

All of the data were subjected to analysis of variance (ANOVA), and mean comparisons were made using Tukey's multiple-range test at a 5\% level of probability.

Supplementary Materials: Supplementary materials can be accessed at: http://www.mdpi.com/1420-3049/ 21/6/799/s1.

Acknowledgments: The authors wish to thank QFB Raúl Manzanilla Rivas for the optimal maintenance of the Capsicum chinense plants used in this work and and L.D.P. Norma Marmolejo for editing graphic material. This work was funded by the CONACYT (México), Grant 168545. F.M.B.E. was the recipient of a CONACYT scholarship for Ph. D. studies.

Author Contributions: M.L.M.-H. conceived and designed the experiments, analyzed the data and wrote the paper; F.M.B.-E. performed a part of the experiments and analyzed the data; L.A.C.-C. performed another part of the experiments; F.A.V.-F. analyzed the data and participated in the paper's writing.

Conflicts of Interest: The authors declare that they have no conflict of interest.

\section{References}

1. Castro-Concha, L.A.; Canché-Chuc, I.; Miranda-Ham, M.L. Determination of antioxidants in fruit tissues from three accessions of habanero pepper (Capsicum chinense Jacq.). J. Mex. Chem. Soc. 2012, 56, 15-18.

2. Silva, L.R.; Acevedo, J.; Pereira, M.J.; Valentão, P.; Andrade, P.B. Chemical assessment and antioxidant capacity of pepper (Capsicum annuum L.) seeds. Food Chem. Toxicol. 2013, 53, 240-248. [CrossRef] [PubMed]

3. Stewart, C.; Kang, B.C.; Liu, K.; Mazourek, M.; Moore, S.L.; Yoo, E.Y.; Kim, B.D.; Paran, I.; Jahn, M.M. The Pun1 gene for pungency in pepper encodes a putative acyltransferase. Plant J. 2005, 42, 675-688. [CrossRef] [PubMed]

4. Ogawa, K.; Murota, K.; Shimura, H.; Furuya, M.; Togawa, Y.; Matsumura, T.; Masuta, C. Evidence of capsaicin synthase activity of the Pun1-encoded protein and its role as a determinant of capsaicinoid accumulation in pepper. BMC Plant Biol. 2015, 15, 93. [CrossRef] [PubMed]

5. Stewart, C.; Mazourek, M.; Stellari, G.M.; O'Connell, M.; Jahn, M. Genetic control of pungency in C. chinense via the Pun1 locus. J. Exp. Bot. 2007, 58, 979-991. [CrossRef] [PubMed] 
6. González-Zamora, A.; Sierra-Campos, E.; Luna-Ortega, J.G.; Pérez-Morales, R.; Ortiz, J.C.R.; García-Hernández, J.L. Characterization of different Capsicum varieties by evaluation of their capsaicinoids content by high performance liquid chromatography. Determination of pungency and effect of high temperature. Molecules 2013, 18, 13471-13486. [CrossRef] [PubMed]

7. Gurung, T.; Techawongstien, S.; Suriharn, B.; Techawongstien, S. Impact of environments on the accumulation of capsaicinoids in Capsicum spp. HortScience 2011, 46, 1576-1581.

8. Johnson, C.D.; Decoteau, D.R. Nitrogen and potassium fertility affects Jalapeño pepper plant growth, pod yield, and pungency. HortScience 1996, 31, 1119-1123.

9. Monforte-González, M.; Guzmán-Antonio, A.; Uuh-Chim, F.; Vázquez-Flota, F. Capsaicin accumulation is related to nitrate content in placentas of habanero peppers (Capsicum chinense Jacq.). J. Sci. Food Agric. 2010, 90, 764-768. [PubMed]

10. Aldana-Iuit, J.G.; Sauri-Duch, E.; Miranda-Ham, M.L.; Castro-Concha, L.A.; Cuevas-Glory, L.F.; Vázquez-Flota, F.A. Nitrate promotes capsaicin accumulation in Capsicum chinense immobilized placentas. BioMed. Res. Int. 2015, 2015, 794084. [CrossRef] [PubMed]

11. Ancona-Escalante, W.R.; Baas-Espinola, F.M.; Castro-Concha, L.A.; Vázquez-Flota, F.A.; Zamudio-Maya, M.; Miranda-Ham, M.L. Induction of capsaicinoid accumulation in placental tissues of Capsicum chinense Jacq. requieres primary ammonia assimilation. Plant Cell Tiss. Org. 2013, 113, 565-570. [CrossRef]

12. Salgado-Garciglia, R.; Ochoa-Alejo, N. Increased capsaicin content in PFP-resistant cells of chili pepper (Capsicum annuum L.). Plant Cell Rep. 1990, 8, 617-620. [CrossRef] [PubMed]

13. Prasad, B.C.N.; Gururaj, H.B.; Kumar, V.; Giridhar, P.; Parimalan, R.; Sharma, A.; Ravishankar, G.A. Influence of 8-methyl-nonenoic acid on capsaicin biosynthesis in in-vivo and in-vitro cell cultures of Capsicum spp. J. Agric. Food Chem. 2006, 54, 1854-1859. [CrossRef] [PubMed]

14. Castro-Concha, L.; Baas-Espinola, F.; Ancona-Escalante, W.; Vázquez-Flota, F.; Miranda-Ham, M.L. Phenylalanine biosynthesis and its relationship to accumulation of capsaicinoids during Capsicum chinense fruit development. Biol. Plantarum 2016, 60, 579-584. [CrossRef]

15. Ray, T.B. Site of action of chlorsulfuron. Inhibition of valine and isoleucine biosynthesis in plants. Plant Physiol. 1984, 75, 827-831. [CrossRef] [PubMed]

16. Samach, A.; Hareven, D.; Gutfinger, T.; Ken-Dror, S.; Lifschitz, E. Biosynthetic threonine deaminase gene of tomato: Isolation, structure, and upregulation in floral organs. PNAS 1991, 88, 2678-2682. [CrossRef] [PubMed]

17. Cho, M.-H.; Corea, O.R.; Yang, H.; Bedgar, D.L.; Laskar, D.D.; Anterola, A.M.; Moog-Anterola, F.A.; Hood, R.L.; Kohalmi, S.E.; Bernards, M.A. Phenylalanine biosynthesis in Arabidopsis thaliana identification and characterization of arogenate dehydratases. J. Biol. Chem. 2007, 282, 30827-30835. [CrossRef] [PubMed]

18. Lancien, M.; Lea, P.J.; Azevedo, R.A. Amino acid synthesis in plastids. In The Structure and Function of Plastids; Wise, R.R., Hoober, J.K., Eds.; Springer: Dordrecht, The Netherlands, 2007; Volume 23, pp. 355-385.

19. Maeda, H.; Shasany, A.K.; Schnepp, J.; Orlova, I.; Taguchi, G.; Cooper, B.R.; Rhodes, D.; Pichersky, E.; Dudareva, N. RNAi suppression of arogenate dehydratase1 reveals that phenylalanine is synthesized predominantly via the arogenate pathway in petunia petals. Plant Cell 2010, 22, 832-849. [CrossRef] [PubMed]

20. Mazourek, M.; Pujar, A.; Borovsky, Y.; Paran, I.; Mueller, L.; Jahn, M.M. A dynamic interface for capsaicinoid systems biology. Plant Physiol. 2009, 150, 1806-1821. [CrossRef] [PubMed]

21. Sukrasno, N.; Yeoman, M. Phenylpropanoid metabolism during growth and development of Capsicum frutescens fruits. Phytochemistry 1993, 32, 839-844. [CrossRef]

22. Contreras-Padilla, M.; Yahia, E.M. Changes in capsaicinoids during development, maturation, and senescence of chile peppers and relation with peroxidase activity. J. Agric. Food Chem. 1998, 46, 2075-2079. [CrossRef]

23. Iwai, K.; Suzuki, T.; Fujiwake, H. Formation and accumulation of pungent principle of hot pepper fruits, capsaicin and its analogues, in Capsicum annuum var. annuum cv. karayatsubusa at different growth stages after flowering. Agric. Biol. Chem. 1979, 43, 2493-2498.

24. Zamudio-Moreno, E.; Echevarría-Machado, I.; Medina-Lara, M.F.; Calva-Calva, G.; Miranda-Ham, M.L.; Martínez-Estévez, M. Role of peroxidases in capsaicinoids degradation in habanero pepper (Capsicum chinense Jacq.) plants grown under water deficit conditions. Aust. J. Crop Sci. 2014, 8, 448-454. 
25. Díaz, J.; Pomar, F.; Bernal, A.; Merino, F. Peroxidases and the metabolism of capsaicin in Capsicum annuum L. Phytochem. Rev. 2004, 3, 141-157. [CrossRef]

26. Nuñez-Palenius, H.; Ochoa-Alejo, N. Effect of phenylalanine and phenylpropanoids on the accumulation of capsaicinoids and lignin in cell cultures of chili pepper (Capsicum annuum L.). In Vitro Cell. Dev. Biol. Plant 2005, 41, 801-805. [CrossRef]

27. Liu, S.; Chen, C.; Chen, G.; Cao, B.; Chen, Q.; Lei, J. RNA-sequencing tag profiling of the placenta and pericarp of pungent pepper provides robust candidates contributing to capsaicinoid biosynthesis. Plant Cell Tiss. Org. 2012, 110, 111-121. [CrossRef]

28. Martínez-López, L.A.; Ochoa-Alejo, N.; Martínez, O. Dynamics of the chili pepper transcriptome during fruit development. BMC Genomics 2014, 15, 143. [CrossRef] [PubMed]

29. Johnson, T.S.; Ravishankar, G.; Venkataraman, L. In vitro capsaicin production by immobilized cells and placental tissues of Capsicum annuum L. grown in liquid medium. Plant Sci. 1990, 70, 223-229. [CrossRef]

30. Ochoa-Alejo, N.; Salgado-Garciglia, R. Phenylalanine ammonia-lyase activity and capsaicin-precursor compounds in p-fluorophenylalanine-resistant and-sensitive variant cells of chili pepper (Capsicum annuum). Physiol. Plant. 1992, 85, 173-179. [CrossRef]

31. Murthy, H.N.; Lee, E.J.; Paek, K.Y. Production of secondary metabolites from cell and organ cultures: strategies and approaches for biomass improvement and metabolite accumulation. Plant Cell Tiss. Org. 2014, 118, 1-16. [CrossRef]

32. Liu, G.; Ji, Y.; Bhuiyan, N.H.; Pilot, G.; Selvaraj, G.; Zou, J.; Wei, Y. Amino acid homeostasis modulates salicylic acid-associated redox status and defense responses in Arabidopsis. Plant Cell 2010, 22, 3845-3863. [CrossRef] [PubMed]

33. Aharoni, A.; Galili, G. Metabolic engineering of the plant primary-secondary metabolism interface. Curr. Opin. Biotech. 2011, 22, 239-244. [CrossRef] [PubMed]

34. Loyola-Vargas, V.M.; Vázquez-Flota, F. An introduction to plant cell culture. In Plant Cell Culture Protocols, 2nd ed.; Loyola-Vargas, V.M., Vázquez-Flota, F., Eds.; Humana Press: Totowa, NJ, USA, 2006; Volume 318, pp. 3-8.

35. Roepke, J.; Salim, V.; Wu, M.; Thamm, A.M.; Murata, J.; Ploss, K.; Boland, W.; De Luca, V. Vinca drug components accumulate exclusively in leaf exudates of Madagascar periwinkle. PNAS 2010, 107, 15287-15292. [CrossRef] [PubMed]

36. Murashige, T.; Skoog, F. A revised medium for rapid growth and bio assays with tobacco tissue cultures. Physiol. Plantarum 1962, 15, 473-497. [CrossRef]

37. Eberlein, C.V.; Guttieri, M.J.; Mallory-Smith, C.A.; Thill, D.C.; Baerg, R.J. Altered acetolactate synthase activity in ALS-inhibitor resistant prickly lettuce (Lactuca serriola). Weed Sci. 1997, 45, 212-217.

38. Connelly, J.A.; Siehl, D.L. Purification of chorismate, prephenate, and arogenate by HPLC. Method Enzymol. 1987, 142, 422-431.

39. Rippert, P.; Matringe, M. Molecular and biochemical characterization of an Arabidopsis thaliana arogenate dehydrogenase with two highly similar and active protein domains. Plant Mol. Biol. 2002, 48, 361-368. [CrossRef] [PubMed]

40. Fischer, R.; Jensen, R. Arogenate dehydratase. Method Enzymol. 1987, 142, 495-502.

41. Peterson, G.L. A simplification of the protein assay method of Lowry et al. which is more generally applicable. Anal. Biochem. 1977, 83, 346-356. [CrossRef]

42. Collins, M.D.; Wasmund, L.M.; Bosland, P.W. Improved method for quantifying capsaicinoids in Capsicum using high-performance liquid chromatography. HortScience 1995, 30, 137-139.

43. Rubio-Piña, J.A.; Vázquez-Flota, F.A. Isolation of functional total RNA from Argemone mexicana tissues. Electron. J. Biotechnol. 2008, 11, 15-16. [CrossRef]

44. Livak, K.J.; Schmittgen, T.D. Analysis of relative gene expression data using real-time quantitative PCR and the $2^{-\Delta \Delta C T}$ method. Methods 2001, 25, 402-408. [CrossRef] [PubMed]

Sample Availability: Samples of the compounds are commercially available.

(C) 2016 by the authors; licensee MDPI, Basel, Switzerland. This article is an open access article distributed under the terms and conditions of the Creative Commons Attribution (CC-BY) license (http:/ / creativecommons.org/licenses/by/4.0/). 